\title{
Nanomedicine of Plant Origin for the Treatment of Metabolic Disorders
}

\author{
Fang $\mathrm{Hu}^{1+}$, Dong-Sheng Sun ${ }^{2 \dagger}$, Kai-Li Wang ${ }^{3}$ and Dan-Ying Shang ${ }^{4 *}$ \\ ${ }^{1}$ Medical Department, Chun'an First People's Hospital (Zhejiang Provincial People's Hospital Chun'an Branch), Hangzhou, China, \\ ${ }^{2}$ Department of Geriatric Medicine, Zhejiang Provincial People's Hospital, Affiliated People's Hospital of Hangzhou Medical \\ College, Hangzhou, China, ${ }^{3}$ Department of Cardiology, Chun'an First People's Hospital (Zhejiang Provincial People's Hospital \\ Chun'an Branch), Hangzhou, China, ${ }^{4}$ Department of Dermatology, Zhejiang Provincial People's Hospital, Affiliated People's \\ Hospital of Hangzhou Medical College, Hangzhou, China
}

\section{OPEN ACCESS}

Edited by:

Rosaria Rinaldi,

University of Salento, Italy

Reviewed by:

Javier Alberto Garza Cervantes, Autonomous University of Nuevo

León, Mexico

Nemany A. N. Hanafy,

Kafrelsheikh University, Egypt

*Correspondence:

Dan-Ying Shang

shangdy1975@163.com

tThese authors have contributed equally to this work

Specialty section:

This article was submitted to

Nanobiotechnology,

a section of the journal

Frontiers in Bioengineering and

Biotechnology

Received: 09 November 2021 Accepted: 22 December 2021

Published: 11 February 2022

Citation:

Hu F, Sun D-S, Wang K-L and Shang D-Y (2022) Nanomedicine of Plant Origin for the Treatment of

Metabolic Disorders.

Front. Bioeng. Biotechnol. 9:811917.

doi: 10.3389/fbioe.2021.811917
Metabolic disorders are major clinical challenges of health that are progressing globally. A concurrence of metabolic disorders such as obesity, insulin resistance, atherogenic dyslipidemia, and systematic hypertension leads to metabolic syndrome. Over the past years, the metabolic syndrome leads to a five- and two-fold rise in diabetes mellitus type II and cardiovascular diseases. Natural products specifically plant extracts have insulinsensitizing, anti-inflammatory, and antioxidant properties and are also considered as an alternative option due to few adverse effects. Nanotechnology is one of the promising strategies, which improves the effectiveness of treatment and limits side effects. This review mainly focuses on plant extract-based nanosystems in the management of the metabolic syndrome. Numerous nano-drug delivery systems, i.e., liposomes, hydrogel nanocomposites, nanoemulsions, micelles, solid lipid, and core-shell nanoparticles, have been designed using plant extracts. It has been found that most of the nano-formulations successfully reduced oxidative stress, insulin resistance, chronic inflammation, and lipid profile in in vitro and in vivo studies as plant extracts interfere with the pathways of metabolic syndrome. Thus, these novel plant-based nanosystems could act as a promising candidate for clinical applications.

Keywords: metabolic disorders, medicinal plants, phytochemicals, nano drug, nano system

\section{INTRODUCTION}

Metabolic disorders happen when the catabolic or anabolic processes are dysfunctional and incline the body to make either excessive or depleted amounts of the essential products, which are needed for the proper functioning of the body. Metabolic disorders have become a worldwide threat as they account for $20 \%-30 \%$ of the world's population (Zimmet et al., 2001). Metabolic disorders are categorized into two groups: one affects the breakdown of amino acids, carbohydrates, or lipids while the other group affects the portions of the cells that produce energy. These metabolic conditions clustered together ultimately result in metabolic syndrome. Metabolic syndrome elevates the risk of several disorders comprising atherogenic dyslipidemia, cardiovascular diseases, central obesity, insulin resistance (diabetes types I and II), hypertension, and cerebrovascular accident (TabatabaeiMalazy et al., 2015; Heindel et al., 2017). Metabolic syndrome is associated with enhanced atherosclerosis, insulin resistance, and obesity which occur due to chronic inflammation and endothelial dysfunction and also increase the risks of cardiovascular diseases and formation of abnormal adipocytokines including pro-inflammatory mediators interleukin-1 and 6 (IL-1, IL-6), tumor necrosis factor $\alpha$ (TNF- $\alpha$ ), adiponectin, and leptin (McCracken et al., 2018). The World 


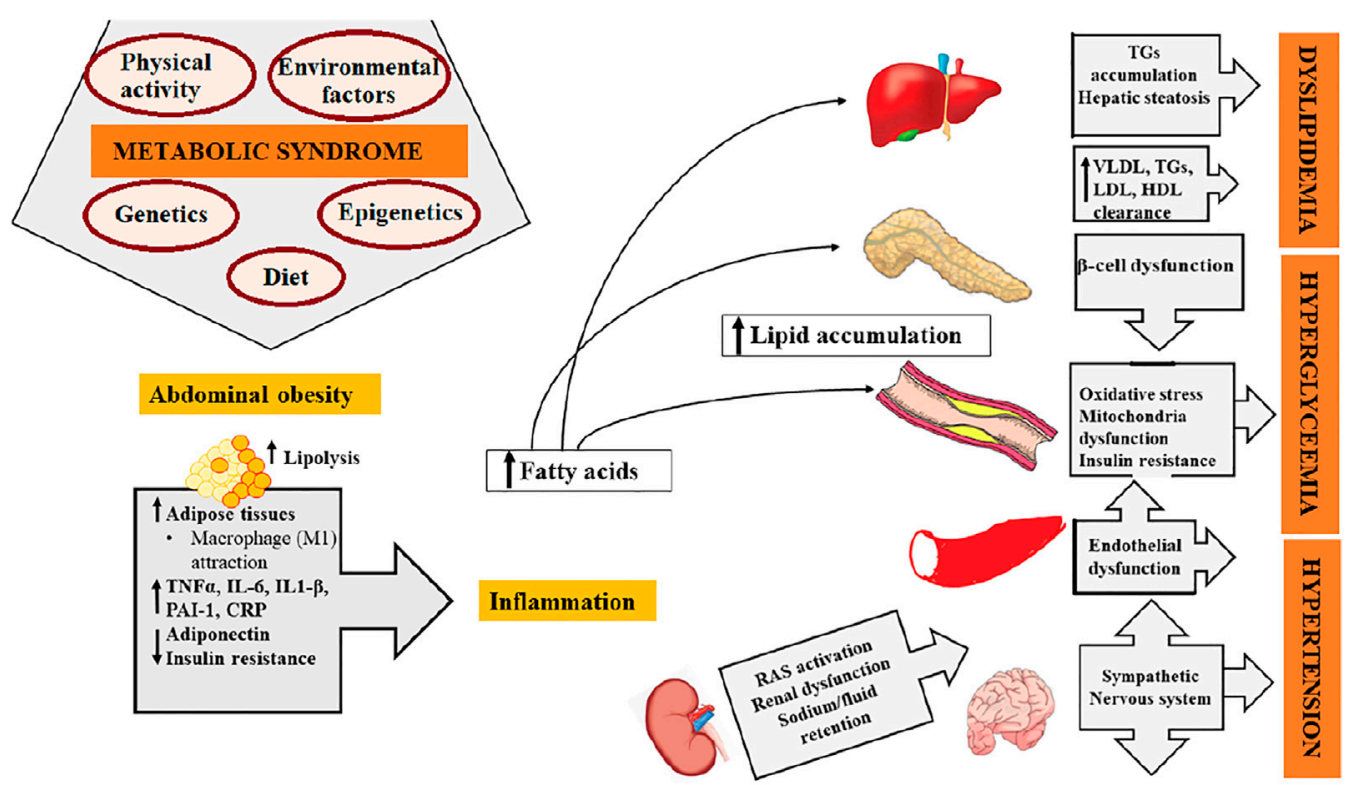

FIGURE 1 | Overview of metabolic syndrome.

Health Organization, International Diabetes Federation, and National Cholesterol Education Program's Adult Treatment Panel III focused on prognosis guidelines of metabolic syndrome, i.e., blood pressure values of systolic $130 \mathrm{mmHg}$ or higher and diastolic $85 \mathrm{mmHg}$ or higher, triglycerides $150 \mathrm{mg} / \mathrm{dl}$ or greater, high-density lipoprotein $<50 \mathrm{mg} / \mathrm{dl}$ in females and $<40 \mathrm{mg} / \mathrm{dl}$ in males, and elevated fasting glucose of $100 \mathrm{mg} / \mathrm{dl}$ or greater (Eckel et al., 2005).

Several presumed mechanisms are underlying the pathophysiology of metabolic syndrome, and the most justifiable mechanism is insulin resistance with fatty acid flux. Other potential mechanisms include chronic inflammation and oxidative stress (Reaven, 1988; Roberts et al., 2013; Pan and Kong, 2018). The non-clearance of free fatty acid from circulation causes insulin resistance in obese individuals. To overcome this resistance, the pancreas secretes a large amount of insulin which results in hyperinsulinemia (Oh et al., 2018). The increased free fatty acid lessens the glucose uptake in muscle; it also causes the induction and suppression of protein kinase in the liver and muscles, respectively, ultimately leading to the elevation of gluconeogenesis (Rochlani et al., 2017). Chronic inflammation involves obesity and elevates insulin resistance, which gives rise to an abnormal production adipocytokines such as leptin, tumor necrosis factor $\alpha$, prothrombotic mediator plasminogen activator inhibitor-1 (Pal-1), interleukin-1, and interleukin-6 (Vaziri et al., 2005; Di Lorenzo et al., 2013). The oxidative stress initiates insulin resistance and abolishes adiponectin production by adipocytes (Furukawa et al., 2004). Adiponectin is an essential anti-inflammatory and anti-atherogenic adipokine and acts as a protective factor against the spreading of severe diseases associated with metabolic disorders and oxidative stress, i.e., diabetes, cardiovascular diseases, and hypertension (Guerre-Millo, 2008; Becic et al., 2018). Adipose tissue stimulates the mineralocorticoid release from adrenal cells and boosts the activity of the renin-angiotensin-aldosterone system. Advancement in sodium retention and vascular tone and at the same time obstruction of norepinephrine reuptake occur which eventually lead to hypertension. Hence, it shows a parallel relationship between obesity and the pathogenesis of hypertension (Cabandugama et al., 2017). An overview of metabolic syndrome is summarized in Figure $\mathbf{1}$.

\section{NANO DRUG DELIVERY SYSTEMS}

Nanotechnology is a promising phenomenon to treat some diseases as it increases the bioavailability, bio-distribution, stability, and solubility of natural compounds. Numerous nano-formulations have been developed by using natural products such as liposomes, core-shell nanoparticles, hydrogels, nano-capsules, nanostructured lipid carriers, nanoemulsions, solid lipid nanoparticles, and micelles. Nanoemulsions are a suitable colloidal system for the controlled delivery of lipophilic molecules (Aswathanarayan and Vittal, 2019). Solid lipid nanoparticles can be modified through different biocompatible and biodegradable solid lipids (Ghasemiyeh and Mohammadi-Samani, 2018). Nanostructured lipid carriers are nano-carriers composed of both solid and liquid lipids (Madane and Mahajan, 2016). Nano-liposomes proved to be the best strategy to deliver and target both hydrophilic and lipophilic constituents (Khorasani et al., 2018). Core-shell nanoparticles also attain attention due to the increase in dispersibility and stability and better conjugation with bioactive compounds (Sounderya and Zhang, 2008).

The conventionally prescribed treatment for metabolic syndrome is the usual administration of drugs to lower blood 


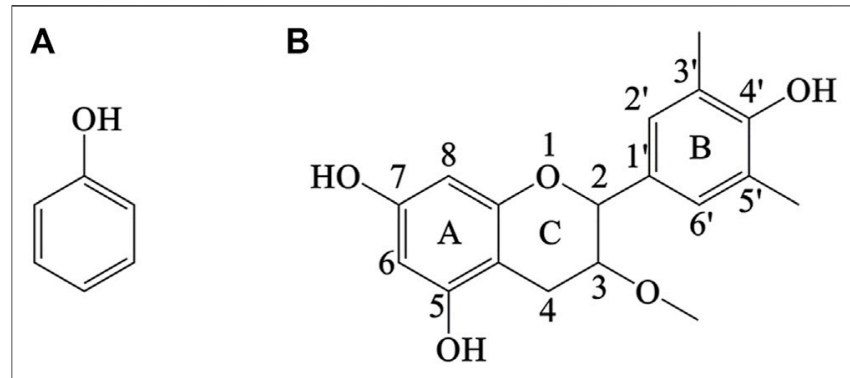

FIGURE 2 | Structure of non-flavinoid (A) and flavinoid (B).

glucose, triglycerides, and blood pressure. However, the longterm use of traditional drugs has a drastic side effect such as flatulence and also exerts weak tolerance for the affected person (Kaur, 2014). Consequently, nano-formulations composed of natural products have been designed to improve the efficacy and delivery of these medications (Grundy, 2016). Many studies suggested that there are several extracts isolated from medicinal plants which have anti-inflammatory, antioxidant, and insulinsensitizing properties (Naseri et al., 2018).

\section{Medical Plant Extract: Polyphenols}

Polyphenols or polyhydroxyphenols are the secondary metabolites of plants that contain several aromatic rings in their structure. They are famously known for their potential health benefits. They exhibit antioxidant, antibacterial, anticancer, and hypoglycemic properties. In addition, they protect against hypertension and cardiovascular diseases (Faridi Esfanjani and Jafari, 2016). Polyphenols are generally classified into two major classes, i.e., flavonoids and nonflavonoids, based on their structures. Flavonoids generally have a 15-carbon skeleton $\left(\mathrm{C}_{6} \mathrm{C}_{3} \mathrm{C}_{6}\right.$ skeleton of carbon) composed of two phenol rings and are connected via an oxygen-containing central pyran ring while the non-flavonoids are composed of one phenol ring (Rambaran, 2020) (Figure 2).

\section{Nanoencapsulation of Polyphenols}

Owing to their tremendous benefits, polyphenols have been extensively studied and various strategies have been devised to limit their side effects and optimize their efficacy. Nanoencapsulation is a potential technology to evade the barriers of poor solubility, less bioavailability and stability, and toxicity of polyphenols (Rambaran, 2020). A flavanol-myricitrin (myricetin-3O-a-rhamnoside) is known for its antioxidant properties. Ahangarpour encapsulated the myricitrin into solid lipid nanoparticles via a cold homogenization method. Both in vivo and in vitro studies (streptozotocin-nicotinamide-induced diabetes mellitus type II mouse and hyperglycemic myotube) demonstrated that myricitrin solid lipid nanoparticles were effective for diabetes and hyperglycemia (Ahangarpour et al., 2018).

Ferulic acid is a polyphenol (phenolic compound) that enhances the diabetic wound healing process due to its antidiabetic, hypoglycemic, angiogenic, and free radical scavenging properties. However, lower bioavailability and less solubility in an aqueous solution hinder its use as an efficient therapeutic drug.
Bairaqi synthesized ferulic acid-encapsulated nanoparticles of poly lactic co-glycolic acid through the nanoprecipitation method. Carbopol 980 hydrogel loaded with ferulic acid and poly lacticco-glycolic acid was formulated for topical application on diabetic wounds. Both were found to be effective than the control groups and exhibited a faster epithelialization process, thus improving the diabetic wound healing process (Bairagi et al., 2018). Another bioflavonoid (flavanone), naringenin has antioxidant and antihyperglycemic properties. However, it is poorly soluble in water and has a low retention time in the intestine. Maity prepared stable therapeutic formulations of naringenin by encapsulating it in core-shell nanoparticles of chitosan and alginate. Naringenin exhibited sustained release and effective antihyperglycemic effects in rat models (Maity et al., 2017). Baicalin is a flavonoid extracted from Scutellaria radix. It demonstrates anti-hyperglycemic effects by inhibiting lipid peroxidation. Due to its less hydrophilicity and poor adsorption, it is favorable to encapsulate baicalin in nanoparticles. To encapsulate baicalin, Shah utilized nanostructured lipid carriers. The results revealed efficient retention of the drug and good stability of baicalin (Xu X et al., 2016).

Recent studies also explain how medicinal plants increase insulin sensitivity and cardiovascular function and moreover decrease gluconeogenesis, inflammation, and oxidative stress (Payab et al., 2020). The formulation of these bioactive compounds in a nanostructured form which ensured the improved bioavailability, stability, and bio-distribution of natural products (Gera et al., 2017). Plant-based nanostructured formulations have an exceptional future to treat metabolic syndrome, but there is no comprehensive review to discuss these formulations. Herein, we provide a detailed review of herbal extracted nano-formulations for metabolic disorders.

\section{PLANT EXTRACTED NANOSYSTEMS FOR METABOLIC DISORDERS}

Nanosystems are administered in the body to increase the targeting efficiency, stability, and efficacy of drugs (Kesharwani et al., 2018). However, some conventional nano-carriers have challenges such as low bioavailability, decreased efficacy, lack of targeted delivery, and high dosage (Subramani et al., 2012). Recently, an in vitro and in vivo investigation revealed that nano-systems increase the site-specific target delivery of drugs (Ponnappan and Chugh, 2015). In the case of diabetes and diabetes-related complications, biotin-fabricated nanoliposomes were found to be effective for the oral administration of insulin without leakage and also facilitated the uptake of insulin via receptor-mediated endocytosis (Zhang et al., 2014). Nano-formulations of conventional drugs increase the efficacy of drugs. Similarly, plant-derived nanosystems which have increased the delivery of phytochemicals and extracts for metabolic disorders are discussed as follows.

\section{Diabetes}

Diabetes mellitus results from defects in either insulin secretion or action or both. Chronic diabetes mellitus is related to age and 
malfunction of various organs: kidneys, blood vessels, heart, and especially eyes. Symptoms of abnormal insulin secretion include weight loss, polydipsia, and blurred vision. Diabetes mellitus is classified into two categories based on glucose regulation: diabetes mellitus type I $(\beta$-cell dysfunction eventually leading to insulin deficiency) and diabetes mellitus type II (non-insulin-dependent diabetes or insulin resistance diabetes) (Salim, 2005). Based on published data, this review focuses on the promising role of herbal medicine incorporated in nanoparticles using nano-biotechnology as an alternative way of treating numerous metabolic disorders (Kopelman, 2000). Thymoquinone is a major bioactive component found in the seed of Nigella sativa (Lamiaceae family) which exhibits protection against diabetes, coronary artery disease, hypertension, oxidative diseases, and respiratory diseases (Farkhondeh et al., 2017). In a recent study, polymeric nanocapsules of thymoquinone and metformin were developed by using a biocompatible polymer gum rosin through the nanoprecipitation method and compared it with pure bioactive metformin and thymoquinone. Different dosages of polymeric nanocapsules and pure metformin were administered to diabetic rats for 21 successive days. The polymeric nanocapsules were stable, spherical, and $<100 \mathrm{~nm}$ in diameter, and thymoquinone also gave a sustained release as compared to pure forms of metformin and thymoquinone. The oral administration of nanocapsules revealed low blood glucose levels and glycolated hemoglobin and further improved the lipid profile. Moreover, the thymoquinone-loaded nanocapsules induced a comparable anti-hyperglycemic effect against metformin nanocapsules, pure thymoquinone, and metformin (Rani et al., 2018). The feature of insulin resistance in diabetes mellitus type II accounts for $90 \%-95 \%$ of the diabetic population which fails insulin function. Recently, Zhang synthesized self-assembled micelles via the conjugation of plant-derived polymer polygalacturonic acid (PGA) and natural insulin sensitizer oleanolic acid (OA) which exhibited as an oral nano-carrier for the treatment of diabetes mellitus type II. The in vitro and in vivo studies revealed that OA-loaded PGA-OA micelles improved the permeability of the gastrointestinal barrier, enhanced the drug intestinal absorption, and maintained the plasma drug concentration for a longer period. Furthermore, the administration of nano-formulation in diabetes mellitus type II model rats demonstrated a tremendous effect on insulin resistance and controlled the blood glucose level and gave a long-termed effect even after its withdrawal (Zhang et al., 2020).

Pouteria sapota is commonly found in Mexico and South America which has a significantly higher antioxidant activity due to the presence of polyphenols (Ma et al., 2004). The green synthesis method was used to prepare silver nanoparticles using the extract of $P$. sapota, and their antidiabetic activity was evaluated in cellular and animal models. The in vitro antidiabetic activity of silver nanoparticles was confirmed due to the decrease in non-enzymatic glycosylation, hindrance of $\alpha$ amylase, and increase in glucose uptake by yeast cells. On the other hand, the biosynthesized silver nanoparticles significantly improved the superoxide dismutase and catalase activity, enhanced the plasma insulin level, and decreased the blood glucose level in streptozotocin-induced rats (Prabhu et al., 2018). Betalain is a natural constitute of cactus pear (Opuntia spp.), red beetroot (Beta vulgaris), pitahayas (Stenocereus spp.), and amaranth (Amaranthaceae) (Sawicki et al., 2018), which displays antidiabetes (Dhananjayan et al., 2017), anticarcinogenic (Amjadi et al., 2019a), and anti-inflammatory properties (Tan et al., 2015). However, poor oral absorption and stability limit its application. To overcome these challenges, Amjadi synthesized betalain-loaded nanoliposomes. A sustained in vitro release profile was observed in both simulated gastric and intestinal fluid. In vivo administration of nano-carriers in streptozotocin-induced rats demonstrated improved regulation of hyperglycemia, oxidative stress, and hyperlipidemia as compared to free betalain. Additionally, the histopathological analysis of diabetic rats revealed reduced tissue in the pancreas, liver, and kidney (Amjadi et al., 2019b).

Selenium is an important trace element in a body that protects the immune system and maintains homeostasis. When selenium is incorporated into nanoparticles, it gives a novel nutritional supplementation with lowered toxicity due to the sustained delivery after its ingestion (Skalickova et al., 2017). Previously, selenium-layered nanoparticles (SeNPs) were synthesized for the delivery of mulberry leaf and Pueraria lobata extracts (MPE) which have hypoglycemia properties and give an antidiabetic effect. The MPE-loaded selenium nanoparticles (MPE-SeNPs) were prepared via solvent diffusion/in-situ reduction method. The MPE-SeNPs were $120 \mathrm{~nm}$ in diameter with $89.38 \%$ and $90.59 \%$ encapsulation efficiency for rutin and puerarin, respectively. The MPE-SeNPs gave a controlled release and improved stability in simulated digestive fluid. The oral administration of MPE-loaded selenium nanoparticles produced a remarkable hypoglycemic effect in control and diabetic rat. An outstanding intestinal permeability was observed in ex vivo intestinal examination (Deng et al., 2019). One of the major causes of diabetes mellitus is oxidative stress; myricitrin is an antioxidant derived from plants, and its solid lipid nanoparticles are much in demand to enhance the antidiabetic and antiapoptotic effects. Myricitrin solid lipid nanoparticles were prepared through the cold homogenization method, and its effects on streptozotocin-nicotinamide-induced diabetes mellitus type II mouse and hyperglycemic myotube were observed. Myricitrin solid lipid nanoparticles demonstrated improved hyperglycemic and diabetes complications (Ahangarpour et al., 2018). Naringenin is a member of the flavonoid family which is found in vegetables and citrus fruits (grapefruits and oranges) (Cavia-Saiz et al., 2010). It has shown anti-hyperglycemic, anticancer (Pateliya et al., 2021), antioxidant (Yin et al., 2020), and anti-inflammatory (Gratieri et al., 2020) properties. The major limitations of naringenin are its poor solubility in water and lower bioavailability due to its metabolism by gut and liver enzymes (Manach et al., 2004). Core-shell nanoparticles of alginate/chitosan loaded with naringenin were prepared through $\mathrm{Na}_{2} \mathrm{SO}_{4}$ and $\mathrm{CaCl}_{2}$ crosslinking to overcome the limitations of naringenin. The 
TABLE 1 | Plant extract-based nanosystems for treatment of diabetes.

\begin{tabular}{|c|c|c|c|c|}
\hline Medicinal plants & Nano-systems & Experimental model & Explanation & References \\
\hline Salvia sclarea & Solid lipid nanoparticles & HFD-induced diabetic mice & $\begin{array}{l}\text { Adipocytes } \\
\text { Arown adipose tissue weight; HDL level; } \\
\text { Improved glycemic level }\end{array}$ & Cerri et al. (2019) \\
\hline Solanum nigrum & Silver nanoparticles & Diabetic rat & $\begin{array}{l}\text { Plmproved dyslipidemia } \\
\text { Blood glucose level }\end{array}$ & $\begin{array}{l}\text { Sengottaiyan et al. } \\
(2016)\end{array}$ \\
\hline Curcumin & Nanoparticles & Diabetic albino rat & $\begin{array}{l}\text { LGlucose-lowering effects; antioxidant effects; } \\
\text { insulin level }\end{array}$ & Abu-Taweel et al. (2020) \\
\hline $\begin{array}{l}\text { Catathelasma } \\
\text { ventricosum }\end{array}$ & Selenium nanoparticles & STZ-induced diabetic rats & $\begin{array}{l}\text { Antidiabetic effect } \\
\text { Body weight; antioxidant activity; lipid level }\end{array}$ & Liu L et al. (2018) \\
\hline Silymarin & Nanostructured lipid carriers & STZ-induced diabetic rats & $\begin{array}{l}\text { Blood glucose level; triglycerides; anti- } \\
\text { hyperalgesic effects }\end{array}$ & Piazzini et al. (2019) \\
\hline Curcumin & Liposomes & STZ-induced diabetic rats & $\begin{array}{l}\text { Hypoglycemic, hypoprotective, and } \\
\text { antioxidant effects } \\
\text { Oxidative stress }\end{array}$ & Bulboacă et al. (2019) \\
\hline Quercetin & $\begin{array}{l}\text { Core-shell nanoparticle (chitosan/ } \\
\text { alginate) }\end{array}$ & Diabetic rat & $\left.\right|_{\text {Hyperlipidemic activity }} ^{\text {Blood glucose level }}$ & $\begin{array}{l}\text { Mukhopadhyay et al. } \\
\text { (2018) }\end{array}$ \\
\hline Annona muricata & Silver nanoparticles & HaCat cell lines & Blood glucose level & Badmus et al. (2020) \\
\hline Talinum portulacifolium & Solid lipid nanoparticles & $\begin{array}{l}\text { STZ- and HFD-induced } \\
\text { diabetic rats }\end{array}$ & $\left.\right|_{\text {Lipid profile }} ^{\text {Blood glucose level; serum insulin; TGs }}$ & Bindu et al. (2014) \\
\hline Myricitrin & Solid lipid nanoparticles & STZ NA-induced diabetic rat & $\begin{array}{l}\text { Loxidative stress } \\
\text { Antioxidant enzyme level }\end{array}$ & $\begin{array}{l}\text { Ahangarpour et al. } \\
\text { (2019) }\end{array}$ \\
\hline
\end{tabular}

HFD, high-feed diet; HDL, high-density lipoprotein; STZ, streptozotocin; TGs, triglycerides; NA, nicotinamide; HaCat, immortalized human keratinocytes.

developed nanoparticles were characterized using different techniques. The encapsulation and amorphous nature of naringenin-loaded core-shell nanoparticles were confirmed by Fourier-transform infrared spectroscopy and x-ray diffractogram, respectively. The average hydrodynamic size of nanoparticles ranges between 150 and $300 \mathrm{~nm}$ with spherical and smooth morphology. The release kinetics of naringenin showed $15 \%$ release in simulated gastric fluid $(\mathrm{pH}=1.2)$ while $>90 \%$ of the drug was released in a sustained manner via simulated intestinal fluid $(\mathrm{pH}=7.4)$. The in vivo study revealed streptozotocin-induced mice reduced the blood glucose levels and enhanced the hypoglycemic effect after oral administration of nanoparticles due to stimulatory activity of naringenin. Furthermore, the histopathological and blood analysis indicated a non-toxicity of nano-system (Maity et al., 2017). Some other nanosystems which are providing effective treatment of diabetes in mice are mentioned in Table $\mathbf{1}$.

\section{Diabetic Wound Healing}

Wound healing is a normal process of a human body after any injury which is achieved through a programmed set of phases, i.e., homeostasis, inflammation, proliferation, and remodeling. These phases should occur in this proper sequence and time frame to properly heal a wound (Guo and DiPietro, 2010). Diabetic wound healing and diabetic foot ulcers are the major causes of amputations which affect $15 \%$ of the patients suffering from diabetes. The major cause of diabetic wound healing is decreased cell growth factor response which abolishes the blood flow and low local angiogenesis (Brem and Tomic-Canic, 2007). During the past few years, nanotechnology has gained attention, which allows a sustained and site-specific delivery of bioactive compounds. Various nanoformulations that are treating diabetic wounds are presented in Table 2. Quercetin (QCT) is found in various medicinal plants, i.e., Hypericum perforatum, Ginkgo biloba, and Sambucus canadensis, which act as a wound 
TABLE 2 | Nanoformulations for diabetic wound healing.

\begin{tabular}{|c|c|c|c|c|}
\hline Medicinal plants & Nano-systems & Model animals & Explanation & References \\
\hline Saraca asoca & Silver nanoparticles & Swiss albino mice & $\hat{A}_{\text {wound contraction }}^{\text {Re-epithelialization; }}$ & Bairagi and Nath (2021 \\
\hline Bambusa bambos & Nanobiocomposite & STZ-induced diabetic rats & $\boldsymbol{A}_{\text {Collagen deposition }}^{\text {Re-epithelialization; }}$ & Singla et al. (2017a) \\
\hline Dendrocalamus hamiltoni & Nanobiocomposite & STZ-induced diabetic rats & $\boldsymbol{A}_{\text {Collagen deposition }}^{\text {Re-epithelialization; }}$ & Singla et al. (2017a) \\
\hline Curcumin & Chitosan nanoparticles & STZ-induced diabetic rats & $\begin{array}{l}\text { Macrophage-induced } \\
\text { Inflammation } \\
\text { Angiogenesis }\end{array}$ & Li et al. (2019) \\
\hline Curcumin & Curcumin nanoparticle-loaded hydrogel & STZ-induced diabetic albino rats & $\begin{array}{l}\text { Wound closure rate; } \\
\text { Granulation tissue } \\
\text { formation; collagen } \\
\text { Deposition. }\end{array}$ & Kamar et al. (2019) \\
\hline Syzygium cumini & Nanocomposites & STZ-induced diabetic rats & $\begin{array}{l}\text { Fast re-epithelialization; neo- } \\
\text { vascularization } \\
\text { Collagen deposition } \\
\text { Anti-inflammatory } \\
\text { Action }\end{array}$ & Singla et al. (2017b) \\
\hline Acalypha indica & Gold nanoparticles & BALB/c mice & $\boldsymbol{A}_{\text {Collagen deposition }}^{\text {Re-epithelialization }}$ & Boomi et al. (2020) \\
\hline Pterocarpus marsupium & Chitosan nanoparticle-loaded hydrogel & STZ-induced diabetic rat & $\begin{array}{l}\text { Re-epithelialization; growth of } \\
\text { granular } \\
\text { Tissues; collagen } \\
\text { Deposition }\end{array}$ & Manne et al. (2021) \\
\hline
\end{tabular}

STZ, streptozotocin; BALB/C mice, albino immunodeficient inbred strain (Bragg albino).

healing, antioxidant, anti-carcinogenic, anti-inflammatory, and anti-fibrotic agent.

Badhwar et al. (2021) prepared a hydrogel with quercetinloaded silver nanoparticles (QCT-AgNPs) which are considered as a gold standard for the treatment of diabetic and burnt wounds. The optimized hydrogel demonstrated $92.09 \%$ entrapment efficiency and smooth surface morphology with a 44.1-nm hydrodynamic diameter. A relatively higher antimicrobial activity against $S$. aureus and E. coli was observed by QCTAgNP hydrogel in comparison with marketed hydrogel. Furthermore, the in vivo results revealed that QCT-AgNP hydrogel decreased the wound gap and enhanced the \% re- epithelialization in the diabetic wound model. Diabetic wounds have serious challenges, which may lead to amputation of the lower extremities. Recently, for the co-delivery of curcumin (CUR) and resveratrol (RES), novel hyaluronic acid (HA)-functionalized chitosan nanoparticles (HA-CUR-RES-CS-NPs) were prepared through the ionic cross-linking method. The fabricated nanoparticles had a particle size $<200 \mathrm{~nm}$, zeta potential $> \pm$ $30 \mathrm{mV}$, and entrapment efficiency of $90 \%$. The in vitro release pattern revealed a non-Fickian diffusion and sustained a release mechanism (Hussain et al., 2020).

A novel nano-hybrid scaffold was prepared by encapsulation of curcumin into chitosan nanoparticles (CUR-CS NPs) followed 
by its impregnation into a collagen scaffold for improved tissue regeneration. The nanoparticles improved the stability and solubility of curcumin. A sustained in vitro release, outstanding biocompatibility, and drug availability were found in the case of a nano-hybrid scaffold. The in vivo wound closure analysis also demonstrated that scaffold-treated wounds healed more efficiently as compared to control and placebo scaffolds. A formation of thick granulation tissue and complete epithelialization were observed in nano-hybrid scaffolds (Karri et al., 2016). Ponnanikajamideen and coworkers (Ponnanikajamideen et al., 2019) used the green method for the plant-mediated synthesis of gold nanoparticles by using the extract of Chamaecostus cuspidatus (insulin plant) to study the hypoglycemic effect in healthy rats and streptozotocin-induced diabetic rats. The green synthesized gold nanoparticles were evaluated through transmission electron microscopy, scanning electron microscopy, and free-radical scavenging activity. The characterized nanoparticles showed spherical morphology with $20 \mathrm{~nm}$ of size. The antidiabetes studies revealed that the extract had a significant hypoglycemic effect as compared to control groups. The free radicals were exhibited in a dose-dependent manner, and $50 \%$ inhibition of free radicals was observed by treating with gold nanoparticles. Moreover, the cutaneous wound healing activity of nanoparticles gave comparable wound recovery in comparison with controls. The toxicity analysis in mice showed controlled blood glucose, glycogen, and serum levels.

Another nano-system is designed to heal diabetic wounds efficiently and increase the availability of curcumin. Curcumin is a polyphenolic compound that has therapeutic effects, but low bioavailability and in-vivo stability have limited its use (Manju and Sreenivasan, 2011). However, the delivery of curcumin through a carrier enhanced the release and also increases its bioavailability. A thermo-sensitive hydrogel in a structure of gelatin microspheres loaded with curcumin was prepared. At first, the self-assembly of curcumin nanoparticles was done followed by its encapsulation in the gelatin macrospheres to respond to matrix metalloproteinase (which are overexpressed in diabetic wounds). The hydrogel containing curcumin loaded in gelatin microspheres was delivered to wound sites to investigate the release and healing efficiency in streptozotocin-induced diabetic mice. The results revealed that this developed delivery system significantly promoted the healing process in mice which have the potential to become a skin drug delivery system (Liu Y et al., 2018).

\section{Obesity}

Obesity is the world's most common disease and is considered a root for many metabolic disorders. Obesity is usually associated with diabetes, cardiovascular diseases, and some forms of cancers. The parameter to define obesity is body mass index. Insulin resistance is a major consequence of obesity. There is a string associated with elevated fat cells and diabetes that makes the release of interleukin- 6 from fat cells that triggers the proinflammatory state indicating obesity (Hill et al., 2003). To treat obesity through nano-systems, Salacia chinensis-loaded gold nanoparticles (SC-AuNPs) were designed to evaluate the antiobesity parameters in obese rats. After the formation of SCAuNPs, the nanoparticles were optimized using different techniques, i.e., ultraviolet-visible spectroscopy, $\mathrm{x}$-ray diffraction, Fourier-transform infrared spectroscopy, scanning electron spectroscopy, energy-dispersive $\mathrm{x}$-ray analysis, and transmission electron microscopy. The treated rats were analyzed to check the change in body weight index, adiponectin, lipid profile, leptin, liver marker enzymes, resistin, inflammatory markers, AMP-activated protein kinase, and liver histo-pathophysiology. The results revealed a spherical morphology, various functional groups, and crystalline nature of SC-AuNPs. The optimized nano-formulation decreased the body weight, resistin, liver marker enzymes, leptin, adipose index, and inflammatory markers. Additionally, the SC-AuNP treatment increased the high-density lipoprotein, AMP-activated protein kinase, and adiponectin. The histopathological profile showed lower hepatocyte degradation due to the SC-AuNPs (Gao et al., 2020). In another study, Ansari and coworkers developed Smilax glabra rhizome-based gold nanoparticles to treat obesity in the streptozotocin-induced rat model. The prepared nanoparticles were characterized using different techniques: ultraviolet-visible spectroscopy, scanning electron spectroscopy, X-ray diffraction, Fourier-transform infrared spectroscopy, and transmission electron microscopy. The ultraviolent-visible spectrum of gold nanoparticles was recorded at the wavelength of $530 \mathrm{~nm}$. The shape and diameter of the gold nanoparticles were hollow and 50-90 nm, respectively. The chemical binding and crystal form of nanoparticles were confirmed through Fourier-transform infrared spectroscopy and X-ray diffraction. Various biochemical parameters, i.e., blood glucose, insulin sufferance and its release, liver markers, lipid profile, and hormones such as adiponectin, leptin, and resistin, indicated the therapeutic effects of nanoparticles on rats. Moreover, the histopathological analysis showed that the distorted liver and cardiac tissues restored membrane, cytoplasm, and nuclei upon treatment with Smilax glabra-derived gold nanoparticles (Ansari et al., 2019).

Saratale prepared silver nanoparticles using the extract of Argyreia nervosa to evaluate in vitro inhibitory effects on aamylase and $a$-glucosidase which are essential enzymes for carbohydrate metabolism. The prepared silver nanoparticles were spherical in shape, and the average diameter was about $15 \mathrm{~nm}$. The $\mathrm{IC}_{50}$ values of $\alpha$-glucosidase and $\alpha$-amylase were 51.7 and $55.5 \mu \mathrm{g} / \mathrm{ml}$, respectively, showing antidiabetic potential. The increase in the surface area and entrapment of free radicals was observed due to the attachment of functional groups of phytochemicals on AgNPs. In addition, the silver nanoparticles displayed strong antibacterial activity against Escherichia coli and Staphylococcus aureus (Saratale et al., 2017). In recent times, numerous nanosystems have been designed for obesity; a few are summarized in Table 3.

The browning of white adipose tissues (WAT) via enhancing thermogenic energy expenditure is one of the therapeutic approaches to regulate the energy imbalance and problems associated with excess body weight. The detrimental effects of this method limited its use. To overcome the foremost issue, ligand fabricated-resveratrol-loaded nanoparticles (L-Rnano) were prepared that specifically bind to decorin receptors on 
TABLE 3 | Plant extract-derived nanosystems for obesity.

\begin{tabular}{|c|c|c|c|c|}
\hline Medicinal plants & Nano-systems & Experimental models & Explanation & References \\
\hline Oleoresin capsicum & $\begin{array}{l}\text { Single-layer and alginate double-layer } \\
\text { nano-emulsion }\end{array}$ & $\begin{array}{l}\text { HFD-induced obesity in rat and } 3 \text { T3- } \\
\text { L1 cell lines }\end{array}$ & $\begin{array}{l}\text { Lipid level; TGs; mRNA level of } \\
\text { PPAR- } \gamma \text {; fatty } \\
\text { Acid-binding protein } \\
\text { Adipocyte }\end{array}$ & Lee et al. (2017) \\
\hline Citrus sinensis & Nano-vesicles & HFHSD mice & $\begin{array}{l}\text { Chylomicron synthesis } \\
\text { TGs; plasma lipids } \\
\text { Villi size }\end{array}$ & $\begin{array}{l}\text { Berger et al. } \\
(2020)\end{array}$ \\
\hline $\begin{array}{l}\text { Dendropanax } \\
\text { morbifera }\end{array}$ & Gold nanoparticles & 3T3-L1 \&amp; HepG2 cell lines & $\begin{array}{l}\text { TGs; PPAR- } \gamma \text {; Jak2 } \\
\text { STAT3; CEBP } \alpha \text {; ap2 expression }\end{array}$ & Yi et al. (2020) \\
\hline
\end{tabular}

HFD, high-feed diet; TGs, triglycerides; PPAR- $\gamma$, peroxisome proliferator-activator receptor-gamma; HFHSD, high-fat, high-sucrose diet; Jak-2, Janus kinase 2 (non-receptor tyrosine kinase); STAT3, signal transducer and activation of transcription 3; CEBP $\alpha$, transcription regulator and enhancer; ap2, a transcription factor expressed in adipose tissues.

adipose stromal cells. The transmission electron microscopic images of L-Rnano showed a spherical shape with a size of 90-110 nm. The intravenous administration of L-Rnano to obese C57BL/6J mice remarkably induced adipose stromal cell differentiation into beige adipocytes which ultimately reduced the $40 \%$ fat mass, inflammation, and enhanced glucose hemostasis (Zu et al., 2021).

In another study, a novel transdermal drug delivery carrier was designed to reduce the volume of subcutaneous adipose tissues. Curcumin-containing poly-vinyl alcohol gelatin nanofibers were synthesized ranging from 200 to $250 \mathrm{~nm}$ in diameter. A uniform method was used for the preparation of transdermal patches. The efficacy of the delivery system in the transport of curcumin through the skin is proved by adjacent arrangement transdermal diffusion cells. The transdermal patches demonstrated reduced the number of adipose tissues up to $4 \%-7 \%$ in model rats (Ariamoghaddam et al., 2018). Similarly, a soy extract-based topical drug delivery system was designed to determine the antiobesity action of soy topically on high-fed dietinduced mice. Nano-sized phytosomes were formulated via the thermogel method. The optimized formulation had encapsulation efficiency \% of 99.89, and gel transformation temperature was recorded to be $31.5^{\circ} \mathrm{C}$. Fourier-transform infrared spectroscopy also confirmed the soy entrapment in the nanosystem due to the formation of a hydrogen bond between $\mathrm{OH}$ groups of soy extract and phosphatidylcholine which eventually increased the permeation rate. The nanophytosome formulation of soybean revealed an improved release pattern $(92.50 \%$ within $2 \mathrm{~h})$. Moreover, the in vivo study on the mouse model demonstrated that soy extract had reduced the size of adipose cells with slight lowering effects on triglycerides and low and very-low-density lipoprotein levels (ElMenshawe et al., 2018).

\section{Dyslipidemia}

Dyslipidemia is one of the major metabolic disorders which occur due to the abnormalities in lipid profile such as higher levels of Apo B, triglycerides, very-low-density lipoprotein, and lowdensity lipoprotein with a decreased level of high-density lipoprotein (Sun et al., 2018). The anomalies in the structure, function, and metabolism of atherogenic and anti-atherogenic lipoproteins result in unhealthy lipid levels (Halpern et al., 2010). Malnutrition and a sedentary lifestyle are the other reasons for dyslipidemia, but a prolonged increase in insulin levels ultimately leads to atherogenic dyslipidemia in different ways. Firstly, the disruption in insulin signaling increases lipolysis which causes the production of free fatty acids and very low-density lipoproteins in hepatocytes. Secondly, the insulin involves in Apo B degradation and lipoprotein lipase activity which causes the hypertriglyceridemia to elevate very-low-density-lipoprotein formation and its storage. Triglycerides are collected from very-low-density lipoprotein/low-density lipoprotein and get exchanged for cholesteryl esters which result in triglyceriderich high-density lipoproteins. These high-density lipoproteins are immediately cleared by hepatic lipases and removed from circulation (Srikanth and Deedwania, 2016).

Dyslipidemia is one of the risks for the progression of cardiovascular diseases such as atherosclerosis, ischemic heart disease, stroke, and coronary heart disease because it leads to the synthesis of free radicals and oxidative stress (Georges et al., 2019; Singh et al., 2016). Conventional medications for dyslipidemia include lovastatin, atorvastatin, simvastatin, and pravastatin which have adverse effects, i.e., myopathy, rhabdomyolysis, and myalgia (Shin et al., 2014; Chu et al., 2015; Wat et al., 2016). To overcome these challenges, natural products such as garlic oil and kenaf oilseed are encapsulated in nanosystems to give antioxidant and anti-hyperlipidemic effects. Few other medicinal plant-extracted nanosystems are explained in Table 4. Garlic (Allium sativum L.) oil consists of sulfurcontaining compounds that have anti-hyperlipidemic (Keshetty et al., 2009), antimicrobial (Zheng et al., 2013), antioxidant, (Ebrahimzadeh-Bideskan et al., 2016), and antidiabetic (Sambu et al., 2015) properties. Ragavan formulated garlic oil nanoemulsion through ultrasonic emulsification, and the optimized nano-emulsion showed spherical morphology with a droplet size of $24.9 \pm 1.11 \mathrm{~nm}$. The zeta potential of formulated nanoemulsion was $-42.63 \pm 1.58 \mathrm{mV}$, and the PDI value was low. Small size, negative zeta potential, and low PDI values collectively 
TABLE 4 | Nanosystems for dyslipidemia.

\begin{tabular}{|c|c|c|c|c|}
\hline $\begin{array}{l}\text { Medicinal } \\
\text { plants }\end{array}$ & Nano-systems & Model animals & Explanation & References \\
\hline Black currant & $\begin{array}{l}\text { Selenium } \\
\text { nanoparticles }\end{array}$ & $\begin{array}{l}\text { Galactose-treated } \\
\text { rats }\end{array}$ & Hypolipidemia Antioxidation activity & $\begin{array}{l}\text { Al-Kurdy and Khadim Khudair } \\
\text { (2020) }\end{array}$ \\
\hline Nigella sativa & Silver nanoparticles & Male adult rats & TGS; cholestrol absorption; LDL-C; oxidative stress & Ali et al. (2019) \\
\hline
\end{tabular}

TG, triglycerides; LDL, low-density lipoprotein; HDL, high-density lipoprotein.

TABLE 5 | Plant extract-based nanosystems for treatment of hypertension.

Medicinal plants

Curcumin

Curcumin

Nanoparticles

Male Sprague Dawley rats

Model animals

HFD-induced mice

PLGA nanoparticles HFD-induced mice

Copaifera sp.
Nano-capsules

Wistar rats

\begin{tabular}{|ll}
\multicolumn{1}{|c}{ Explanation } & \multicolumn{1}{c}{ References } \\
\hline $\begin{array}{l}\text { Systolic blood pressure } \\
\text { Ventricular stiffness; } \\
\text { Fat deposition }\end{array}$ & du Preez et al. (2019) \\
$\begin{array}{l}\text { Right ventricular wall thickness; } \\
\text { right Ventricle weight/body } \\
\text { ratio; oxidative stress }\end{array}$ & Rice et al. (2015) \\
\hline $\begin{array}{l}\text { Right ventricle hypertrophy; } \\
\text { oxidative Stress; } \\
\text { pulmonary } \\
\text { Vascular resistance }\end{array}$ & Campos et al. (2017) \\
\hline
\end{tabular}

PLGA, poly (lactic-co-glycolic acid); HFD, high-feed diet.

gave stability to the nano-system. The acute toxicity study revealed that nano-emulsion of garlic oil with Tween as a surfactant did not exhibit any toxicity. Garlic oil nanoemulsion when administered to dyslipidemic Wistar rats demonstrated a significant effect in lowering the lipid profile in comparison with pure drug (atorvastatin) and garlic oil. In addition, the lipid deposits in hepatic tissues were also reduced when analyzed under Oil Red O staining which suggested that the developed nano-emulsion is a promising candidate for treating dyslipidemia (Ragavan et al., 2017). Ziziphus jujube (jujube) is a medicinal fruit that has antioxidant, anti-inflammatory, hepatoprotective, antibacterial, and anti-inflammation properties. The green synthesis of gold nanoparticles using jujube was done followed by its characterization based on transmission electron microscopy and X-ray diffraction. The smooth spherical morphology and 7-27-nm-sized gold nanoparticles were obtained. For in vivo studies, different doses of gold nanoparticles were administered to streptozotocin-induced diabetic rats, and lipid profile, body weight, insulin, and liver oxidative markers were evaluated. The results showed a significant decrease in the levels of liver, insulin, triglycerides, cholesterol, and total antioxidant capacity (Javanshir et al., 2020).

Kenaf (Hibiscus cannabinus L.) seed oil has phytosterol and saponin (Shi et al., 2004) which reduce the cholesterol level, but the hydrophobic nature and poor bioavailability have limited its applications. Nano-emulsion and macro-emulsion of kenaf seed oil were prepared to investigate liver oxidative status, lipid serum profile, and histopathological changes in high cholesterol dietinduced rats. The kenaf seed oil in water nanoemulsion displayed narrow particle size distribution and higher zeta potential indicating the high electrostatic interaction between the particles. The stability and encapsulation and bioavailability of kenaf seed oil in water nano-emulsion were higher than macroemulsion. In vivo studies revealed that the nanoemulsion declined the accumulation of fat droplets in the liver, lowered cholesterol, decreased the number of endogenous antioxidants in the liver, and controlled the weight in high cholesterol diet-induced rats. Furthermore, the histopathological analysis on rats suggested an accelerated renewal of liver cells after injury was observed due to nanoemulsion (Cheong et al., 2018).

\section{Hypertension}

Hypertension is becoming a serious threat worldwide, which refers to the rise in arterial blood pressure. An adequate amount of blood is required throughout the circulation; otherwise, it damages the eyes, kidneys, and brains and also leads to heart-related problems, i.e., cardiac failure, myocardial infarction, stroke, and peripheral vascular disease (Alam et al., 2017; Kikuchi et al., 2018). A modified approach is needed to limit cardiovascular diseases. In a study, curcumin-loaded poly (lactic- 


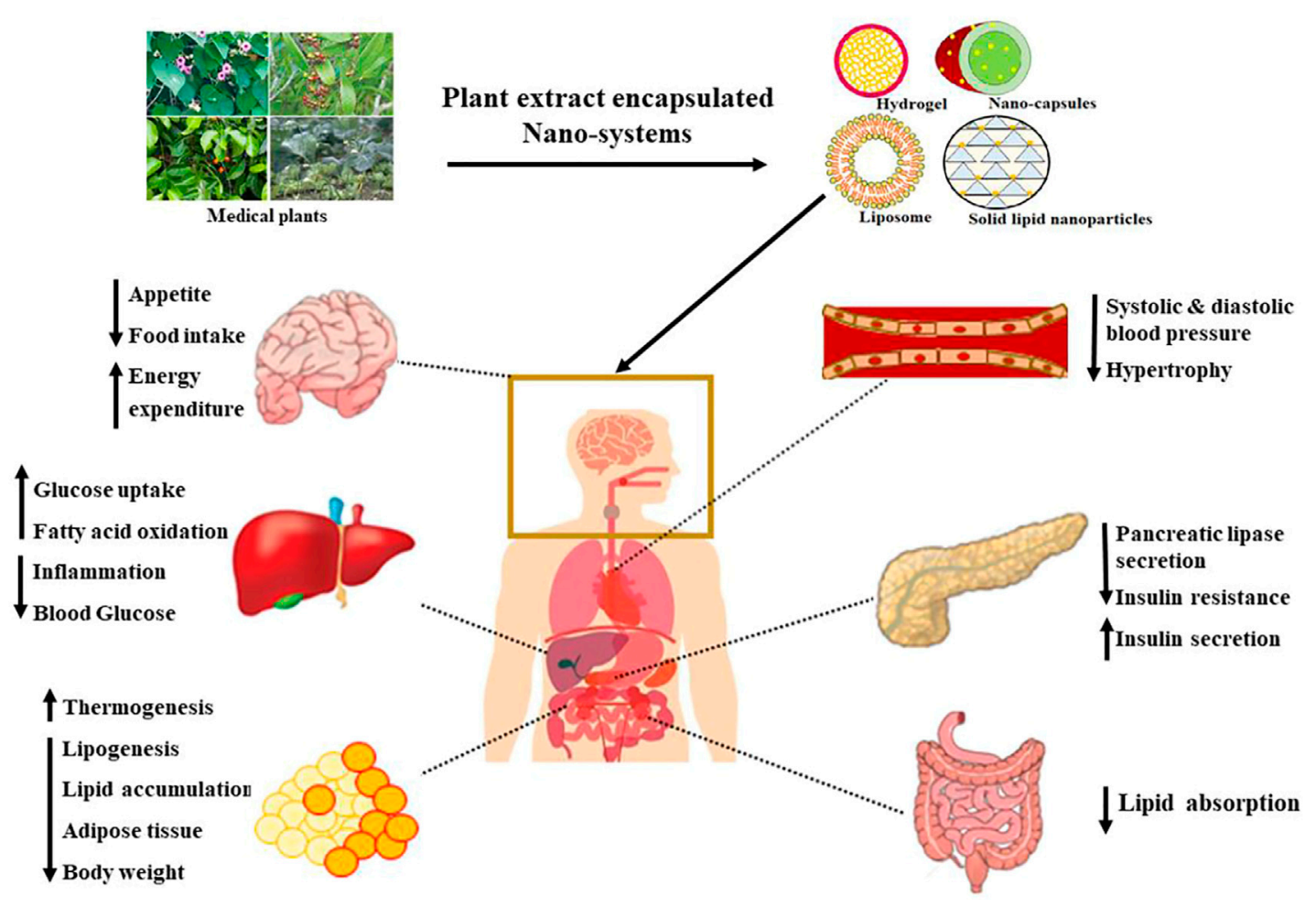

FIGURE 3 | Importance of plant-extract-encapsulated nanosystems for metabolic disorders.

co-glycolic acid) nanoparticles were prepared by a single emulsion method to evaluate the cardiovascular parameters in high-fed diet Wistar rats. The hydrodynamic diameter and zeta potential of nanoparticles were obtained to be $315-320 \mathrm{~nm}$ and $-29 \mathrm{mV}$, respectively. The greater size marked due to the higher molecular weight of poly (lactic-co-glycolic acid) and negative zeta potential confirmed the stability of the nano-system in circulation. The results revealed that a 20 -fold lower dosage of curcumin in poly (lactic-co-glycolic acid) nanoparticles normalized the blood pressure, reduced liver fat deposition, and improved ventricular inflammation and fibrosis (du Preez et al., 2019).

High blood pressure in the arteries of the lung causes a progressive disorder known as pulmonary arterial hypertension. Inflammation, oxidative stress, and nitric oxide are involved in the development of pulmonary arterial hypertension (Xu et al., 2017). It disturbs the vascular function by increasing the vascular resistance and obstructing the pulmonary artery, which eventually leads to right ventricular hypertrophy and right-sided heart failure. The medicinal plants which have antioxidant and anti-inflammatory activities can treat pulmonary arterial hypertension (Xiang et al., 2018; Meghwani et al., 2018; Xu D et al., 2016). Copaiba oil is an oil-resin that comes from an Amazonian tree and is used as an herbal treatment in Brazil. The major composition of copaiba oil is $\beta$ caryophyllene which is a calcium channel blocker. The blocker has an antioxidant and anti-inflammatory action and also has inhibitory effects on cell growth (Rasheed et al., 2015; Ames-Sibin et al., 2018). Copaiba oil-loaded nanocapsules were prepared to investigate the monocrotaline-induced pulmonary arterial hypertension. The free copaiba oil and nanocapsules enhanced the sulfhydryl groups, superoxide dismutase, and Nrf2 (antioxidant transcription factor) and removed the oxidized glutathione concentration, but the nano encapsulated oil was more effective than free copaiba oil. Both the oil and nanoformulation significantly reduced the right ventricular hypertrophy index. However, the nanosystem did not show any effect on pulmonary vascular resistance. Furthermore, the nano-capsules composed of pectin and copaiba oil have enhanced the pharmacological effect (Campos et al., 2017). In short, the nano-encapsulation of copaiba oil provides the favorable delivery and also increased its efficiency. Some nano-formulated medicinal plants that have given different therapeutic effects are listed in Table 5.

\section{CONCLUSION}

Metabolic syndrome is a complex disorder comprising insulin resistance, hyperinsulinemia, and impaired glucose tolerance. There is a need for an effective strategy to treat the complications in the pathophysiology of metabolic syndrome. Despite extensive research on the therapeutic effects of plantderived bioactive compounds, their delivery and bioavailability are always troublesome. Over the past few years, the nanoencapsulation of bioactive compounds has revolutionized 
the pharmaceutical and clinical industries. These nanosystems have improved not only the bioavailability but also the efficacy, stability, and solubility of plant extracts. When these plant extract-encapsulated nanoformulations are administered to the body, some metabolic changes are expected to occur which are summarized in Figure 3.

Diabetes mellitus is a challenging and problematic disease; however, nano-formulations of plant extracts have shown remarkable antidiabetic effects in comparison with conventional treatments. Thymoquinone incorporated in nanocapsules, betalain within selenium nanoparticles, naringenin-encapsulated core-shell nanoparticles, and various nanosystems exhibited hypoglycemia and low lipids levels, hence providing effective alternative therapeutics for diabetes. Similarly, the anti-inflammatory and antibacterial properties of plant extract-based nanosystems have provided tremendous advantages in rapid wound healing. Among all the studies in this review, thermosensitive hydrogel loaded with curcumin nanoparticles showed a fast recovery in streptozotocin-induced mice. The delivery of plant extract via chitosan/alginate core-shell nanoparticles induced a significant hypoglycemic effect and decreased oxidative stress in antiobesity therapy. The nanoemulsions of sulfur-containing medicinal plants such

\section{REFERENCES}

Abu-Taweel, G. M., Attia, M. F., Hussein, J., Mekawi, E. M., Galal, H. M., Ahmed, E. I., et al. (2020). Curcumin Nanoparticles Have Potential Antioxidant Effect and Restore Tetrahydrobiopterin Levels in Experimental Diabetes. Biomed. Pharmacother. 131, 110688. doi:10.1016/J.BIOPHA.2020.110688

Ahangarpour, A., Oroojan, A. A., Khorsandi, L., Kouchak, M., and Badavi, M. (2019). Antioxidant, Anti-apoptotic, and Protective Effects of Myricitrin and its Solid Lipid Nanoparticle on Streptozotocin-Nicotinamide-Induced Diabetic Nephropathy in Type 2 Diabetic Male Mice. Iran. J. Basic Med. Sci. 22 (12), 1424-1431. doi:10.22038/IJBMS.2019.13989

Ahangarpour, A., Oroojan, A. A., Khorsandi, L., Kouchak, M., and Badavi, M. (2018). Solid Lipid Nanoparticles of Myricitrin Have Antioxidant and Antidiabetic Effects on Streptozotocin-Nicotinamide-Induced Diabetic Model and Myotube Cell of Male Mouse. Oxidative Med. Cell Longevity 2018, 1-18. doi:10.1155/2018/7496936

Al-Kurdy, M. J., and Khadim Khudair, K. (2020). The Effect of Black Currant Selenium Nanoparticles on Dyslipidemia and Oxidant-Antioxidant Status in D-Galactose Treated Rats. Kufa J. Vet. Med. Sci. 11, 23-38. http://journals. uokufa.edu.iq/index.php/kjvs/article/view/9357

Alam, T., Khan, S., Gaba, B., Haider, M. F., Baboota, S., and Ali, J. (2017). Nanocarriers as Treatment Modalities for Hypertension. Drug Deliv. 24 (1), 358-369. doi:10.1080/10717544.2016.1255999

Ali, Z. S., and Khudair, K. K. (2019). Synthesis, Characterization of Silver Nanoparticles Using Nigella Sativa Seeds and Study Their Effects on the Serum Lipid Profile and DNA Damage on the Rats' Blood Treated with Hydrogen Peroxide. Iraqi J. Vet. Med. 43 (2), 23-37. doi:10.30539/ IRAQIJVM.V43I2.526

Ames-Sibin, A. P., Barizão, C. L., Castro-Ghizoni, C. V., Silva, F. M. S., SáNakanishi, A. B., Bracht, L., et al. (2018). $\beta$-Caryophyllene, the Major Constituent of Copaiba Oil, Reduces Systemic Inflammation and Oxidative Stress in Arthritic Rats. J. Cel. Biochem. 119 (12), 10262-10277. doi:10.1002/ JCB.27369

Amjadi, S., Hamishehkar, H., and Ghorbani, M. (2019). A Novel Smart PEGylated Gelatin Nanoparticle for Co-delivery of Doxorubicin and Betanin: A Strategy for Enhancing the Therapeutic Efficacy of Chemotherapy. Mater. Sci. Eng. C 97, 833-841. doi:10.1016/J.MSEC.2018.12.104 as Allium sativum L. and kenaf seed oil showed the highest antihyperlipidemic effect. Furthermore, the nanoparticles, nanoemulsions, and nanocapsules displayed a curative effect on hypertension and pulmonary arterial hypertension.

The delivery of phytochemicals by utilizing nanotechnology facilitated conventional medicines to link with modern techniques and improve their therapeutic efficacy. This review aims to gather all the in vitro and in vivo researches regarding plant-based nano-formulations on metabolic disorders.

\section{AUTHOR CONTRIBUTIONS}

D-YS provided the idea for this study. The manuscript was written by FH, D-SS, and K-LW. K-LW also assisted in the editing of the manuscript.

\section{FUNDING}

This work was supported by the Zhejiang Provincial Science and Technology Projects (No. LGF20H020009 to D-SS).

Amjadi, S., Mesgari Abbasi, M., Shokouhi, B., Ghorbani, M., and Hamishehkar, H. (2019). Enhancement of Therapeutic Efficacy of Betanin for Diabetes Treatment by Liposomal Nanocarriers. J. Funct. Foods 59, 119-128. doi:10. 1016/J.JFF.2019.05.015

Ansari, S., Bari, A., Ullah, R., Mathanmohun, M., Veeraraghavan, V. P., and Sun, Z. (2019). Gold Nanoparticles Synthesized with Smilax Glabra Rhizome Modulates the Anti-obesity Parameters in High-Fat Diet and Streptozotocin Induced Obese Diabetes Rat Model. J. Photochem. Photobiol. B: Biol. 201, 111643. doi:10.1016/J.JPHOTOBIOL.2019.111643

Ariamoghaddam, A. r., Ebrahimi-Hosseinzadeh, B., Hatamian-Zarmi, A., and Sahraeian, R. (2018). In Vivo anti-obesity Efficacy of Curcumin Loaded Nanofibers Transdermal Patches in High-Fat Diet Induced Obese Rats. Mater. Sci. Eng. C 92, 161-171. doi:10.1016/J.MSEC.2018. 06.030

Aswathanarayan, J. B., and Vittal, R. R. (2019). Nanoemulsions and Their Potential Applications in Food Industry. Front. Sustain. Food Syst. 3, 95. doi:10.3389/ FSUFS.2019.00095

Badhwar, R., Mangla, B., Neupane, Y. R., Khanna, K., and Popli, H. (2021). Quercetin Loaded Silver Nanoparticles in Hydrogel Matrices for Diabetic Wound Healing. Nanotechnology 32 (50), 505102. doi:10.1088/1361-6528/ AC2536

Badmus, J. A., Oyemomi, S. A., Adedosu, O. T., Yekeen, T. A., Azeez, M. A., Adebayo, E. A., et al. (2020). Photo-assisted Bio-Fabrication of Silver Nanoparticles Using Annona Muricata Leaf Extract: Exploring the Antioxidant, Anti-diabetic, Antimicrobial, and Cytotoxic Activities. Heliyon 6 (11), e05413. doi:10.1016/J.HELIYON.2020.E05413

Bairagi, B., and Nath, D. (2021). Wound Healing and Antimicrobial Property of Phytofabricated Silver Nanoparticle by Saraca Asoca Bark Extract on Diabetic Wound in Mice. Lect. Notes Bioeng., 475-484. doi:10.1007/978-981-157409-2_48

Bairagi, U., Mittal, P., Singh, J., and Mishra, B. (2018). Preparation, Characterization, and In Vivo Evaluation of Nano Formulations of Ferulic Acid in Diabetic Wound Healing. Drug Develop. Ind. Pharm. 44 (11), 1783-1796. doi:10.1080/03639045.2018.1496448

Becic, T., Studenik, C., and Hoffmann, G. (2018). Exercise Increases Adiponectin and Reduces Leptin Levels in Prediabetic and Diabetic Individuals: Systematic Review and Meta-Analysis of Randomized Controlled Trials. Med. Sci. 6 (4), 97. doi:10.3390/MEDSCI6040097 
Berger, E., Colosetti, P., Jalabert, A., Meugnier, E., Wiklander, O. P. B., Jouhet, J., et al. (2020). Use of Nanovesicles from Orange Juice to Reverse Diet-Induced Gut Modifications in Diet-Induced Obese Mice. Mol. Ther. - Methods Clin. Develop. 18, 880-892. doi:10.1016/J.OMTM.2020.08.009

Bindu, R. H., Lakshmi, S. M., Himaja, N., Nirosha, K., and Pooja, M. (2014). Formulation Characterization and Antidiabetic Evaluation of Talinum Portulacifolium (Forssk.) Loaded Solid Lipid Nanoparticles in Streptozotocin and High Fat Diet Induced Diabetic Rats. J. Glob. Trends Pharm. Sci. 5 (4), 2108-2114.

Boomi, P., Ganesan, R., Prabu Poorani, G., Jegatheeswaran, S., Balakumar, C., Gurumallesh Prabu, H., et al. (2020). Phyto-Engineered Gold Nanoparticles (AuNPs) with Potential Antibacterial, Antioxidant, and Wound Healing Activities under In Vitro and In Vivo Conditions. Ijn 15, 7553-7568. doi:10. 2147/IJN.S257499

Brem, H., and Tomic-Canic, M. (2007). Cellular and Molecular Basis of Wound Healing in Diabetes. J. Clin. Invest. 117 (5), 1219-1222. doi:10.1172/JCI32169

Bulboacă, A., Porfire, A., Tefas, L., Boarescu, P., Bolboacă, S., Stănescu, I., et al. (2019). Liposomal Curcumin Is Better Than Curcumin to Alleviate Complications in Experimental Diabetic Mellitus. Molecules 24 (5), 846. doi:10.3390/MOLECULES24050846

Cabandugama, P. K., Gardner, M. J., and Sowers, J. R. (2017). The Renin Angiotensin Aldosterone System in Obesity and Hypertension. Med. Clin. North America 101 (1), 129-137. doi:10.1016/J.MCNA.2016.08.009

Campos, C., de Castro, A. L., Tavares, A. M. V., Fernandes, R. O., Ortiz, V. D., Barboza, T. E., et al. (2017). Effect of Free and Nanoencapsulated Copaiba Oil on Monocrotaline-Induced Pulmonary Arterial Hypertension. J. Cardiovasc. Pharmacol. 69 (2), 79-85. doi:10.1097/FJC.0000000000000442

Cavia-Saiz, M., Busto, M. D., Pilar-Izquierdo, M. C., Ortega, N., Perez-Mateos, M., and Muñiz, P. (2010). Antioxidant Properties, Radical Scavenging Activity and Biomolecule protection Capacity of Flavonoid Naringenin and its Glycoside Naringin: a Comparative Study. J. Sci. Food Agric. 90 (7), 1238-1244. doi:10. 1002/JSFA.3959

Cerri, G. C., Lima, L. C. F., Lelis, D. d. F., Barcelos, L. d. S., Feltenberger, J. D., Mussi, S. V., et al. (2019). Sclareol-loaded Lipid Nanoparticles Improved Metabolic Profile in Obese Mice. Life Sci. 218, 292-299. doi:10.1016/J.LFS.2018.12.063

Cheong, A. M., Jessica Koh, J. X., Patrick, N. O., Tan, C. P., and Nyam, K. L. (2018). Hypocholesterolemic Effects of Kenaf Seed Oil, Macroemulsion, and Nanoemulsion in High-Cholesterol Diet Induced Rats. J. Food Sci. 83 (3), 854-863. doi:10.1111/1750-3841.14038

Chu, S.-M., Shih, W.-T., Yang, Y.-H., Chen, P.-C., and Chu, Y.-H. (2015). Use of Traditional Chinese Medicine in Patients with Hyperlipidemia: A PopulationBased Study in Taiwan. J. Ethnopharmacology 168, 129-135. doi:10.1016/J.JEP. 2015.03.047

Deng, W., Wang, H., Wu, B., and Zhang, X. (2019). Selenium-layered Nanoparticles Serving for Oral Delivery of Phytomedicines with Hypoglycemic Activity to Synergistically Potentiate the Antidiabetic Effect. Acta Pharmaceutica Sinica B 9 (1), 74-86. doi:10.1016/J.APSB.2018.09.009

Dhananjayan, I., Kathiroli, S., Subramani, S., and Veerasamy, V. (2017). Ameliorating Effect of Betanin, a Natural Chromoalkaloid by Modulating Hepatic Carbohydrate Metabolic Enzyme Activities and Glycogen Content in Streptozotocin - Nicotinamide Induced Experimental Rats. Biomed. Pharmacother. 88, 1069-1079. doi:10.1016/J.BIOPHA.2017.01.146

Di Lorenzo, C., Dell'Agli, M., Colombo, E., Sangiovanni, E., and Restani, P. (2013). Metabolic Syndrome and Inflammation: A Critical Review ofIn Vitroand Clinical Approaches for Benefit Assessment of Plant Food Supplements. Evidence-Based Complement. Altern. Med. 2013, 1-10. doi:10.1155/2013/782461

du Preez, R., Pahl, J., Arora, M., Ravi Kumar, M. N. V., Brown, L., and Panchal, S. K. (2019). Low-Dose Curcumin Nanoparticles Normalise Blood Pressure in Male Wistar Rats with Diet-Induced Metabolic Syndrome. Nutrients 11 (7), 1542. doi:10.3390/NU11071542

Ebrahimzadeh-Bideskan, A.-R., Hami, J., Alipour, F., Haghir, H., Fazel, A.-R., and Sadeghi, A. (2016). Protective Effects of Ascorbic Acid and Garlic Extract against lead-induced Apoptosis in Developing Rat hippocampus. Metab. Brain Dis. 31531 (5), 1123-1132. doi:10.1007/S11011-016-9837-7

Eckel, R. H., Grundy, S. M., and Zimmet, P. Z. (2005). The Metabolic Syndrome. The Lancet 365 (9468), 1415-1428. doi:10.1016/S0140-6736(05)66378-7

El-Menshawe, S., Ali, A., Rabeh, M., and Khalil, N. (2018). Nanosized Soy Phytosome-Based Thermogel as Topical Anti-obesity Formulation: an
Approach for Acceptable Level of Evidence of an Effective Novel Herbal Weight Loss Product. Ijn 13, 307-318. doi:10.2147/IJN.S153429

Faridi Esfanjani, A., and Jafari, S. M. (2016). Biopolymer Nano-Particles and Natural Nano-Carriers for Nano-Encapsulation of Phenolic Compounds. Colloids Surf. B: Biointerfaces 146, 532-543. doi:10.1016/J.COLSURFB.2016.06.053

Farkhondeh, T., Samarghandian, S., and Borji, A. (2017). An Overview on Cardioprotective and Anti-diabetic Effects of Thymoquinone. Asian Pac. J. Trop. Med. 10 (9), 849-854. doi:10.1016/J.APJTM.2017.08.020

Furukawa, S., Fujita, T., Shimabukuro, M., Iwaki, M., Yamada, Y., Nakajima, Y., et al. (2004). Increased Oxidative Stress in Obesity and its Impact on Metabolic Syndrome. J. Clin. Invest. 114 (12), 1752-1761. doi:10.1172/ JCI21625

Gao, L., Hu, Y., Hu, D., Li, Y., Yang, S., Dong, X., et al. (2020). Anti-obesity Activity of Gold Nanoparticles Synthesized from Salacia Chinensis Modulates the Biochemical Alterations in High-Fat Diet-Induced Obese Rat Model via AMPK Signaling Pathway. Arabian J. Chem. 13 (8), 6589-6597. doi:10. 1016/J.ARABJC.2020.06.015

Georges, N., Simon, A., Naim, B., Georges, N., Georges, A. F., and Tanios, A. (2019). Universal Screening Program for Lipid Disorders in 2-10 Years Old Lebanese Children: A New Approach. Int. J. Pediatr. Adolesc. Med. 6 (3), 101-108. doi:10.1016/J.IJPAM.2019.05.003

Gera, M., Sharma, N., Ghosh, M., Huynh, D. L., Lee, S. J., Min, T., et al. (2017). Nanoformulations of Curcumin: an Emerging Paradigm for Improved Remedial Application. Oncotarget 8 (39), 66680-66698. doi:10.18632/ ONCOTARGET.19164

Ghasemiyeh, P., and Mohammadi-Samani, S. (2018). Solid Lipid Nanoparticles and Nanostructured Lipid Carriers as Novel Drug Delivery Systems: Applications, Advantages and Disadvantages. Res. Pharma Sci. 13 (4), 288. doi:10.4103/1735-5362.235156

Gratieri, T., Pinho, L. A. G., Oliveira, M. A., Sa-Barreto, L. L., Marreto, R. N., Silva, I. C., et al. (2020). Hydroxypropyl- $\beta$-cyclodextrin-complexed Naringenin by Solvent Change Precipitation for Improving Anti-inflammatory Effect In Vivo. Carbohydr. Polym. 231, 115769. doi:10.1016/J.CARBPOL.2019.115769

Grundy, S. M. (2016). Metabolic Syndrome Update. Trends Cardiovasc. Med. 26 (4), 364-373. doi:10.1016/J.TCM.2015.10.004

Guerre-Millo, M. (2008). Adiponectin: An Update. Diabetes Metab. 34 (1), 12-18. doi:10.1016/J.DIABET.2007.08.002

Guo, S., and DiPietro, L. A. (2010). Factors Affecting Wound Healing. J. Dent Res. 89 (3), 219-229. doi:10.1177/0022034509359125

Halpern, A., Mancini, M. C., Magalhães, M. E. C., Fisberg, M., Radominski, R., Bertolami, M. C., et al. (2010). Metabolic Syndrome, Dyslipidemia, Hypertension and Type 2 Diabetes in Youth: from Diagnosis to Treatment. Diabetol. Metab. Syndr. 2 (1), 1-20. doi:10.1186/1758-5996-2-55

Heindel, J. J., Blumberg, B., Cave, M., Machtinger, R., Mantovani, A., Mendez, M. A., et al. (2017). Metabolism Disrupting Chemicals and Metabolic Disorders. Reprod. Toxicol. 68, 3-33. doi:10.1016/J.REPROTOX.2016.10.001

Hill, J. O., Wyatt, H. R., Reed, G. W., and Peters, J. C. (2003). Obesity and the Environment: Where Do We Go from Here. Science 299 (5608), 853-855. doi:10.1126/SCIENCE.1079857

Hussain, Z., Pandey, M., Choudhury, H., Ying, P. C., Xian, T. M., Kaur, T., et al. (2020). Hyaluronic Acid Functionalized Nanoparticles for Simultaneous Delivery of Curcumin and Resveratrol for Management of Chronic Diabetic Wounds: Fabrication, Characterization, Stability and In Vitro Release Kinetics. J. Drug Deliv. Sci. Techn. 57, 101747. doi:10.1016/J.JDDST.2020.101747

Javanshir, R., Honarmand, M., Hosseini, M., and Hemmati, M. (2020). Antidyslipidemic Properties of green Gold Nanoparticle: Improvement in Oxidative Antioxidative Balance and Associated Atherogenicity and Insulin Resistance. Clin. Phytosci 616 (1), 1-10. doi:10.1186/S40816-020-00224-6

Kamar, S. S., Abdel-Kader, D. H., and Rashed, L. A. (2019). Beneficial Effect of Curcumin Nanoparticles-Hydrogel on Excisional Skin Wound Healing in Type-I Diabetic Rat: Histological and Immunohistochemical Studies. Ann. Anat. - Anatomischer Anzeiger 222, 94-102. doi:10.1016/J.AANAT.2018.11.005

Karri, V. V. S. R., Kuppusamy, G., Talluri, S. V., Mannemala, S. S., Kollipara, R., Wadhwani, A. D., et al. (2016). Curcumin Loaded Chitosan Nanoparticles Impregnated into Collagen-Alginate Scaffolds for Diabetic Wound Healing. Int. J. Biol. Macromolecules 93, 1519-1529. doi:10.1016/J.IJBIOMAC.2016.05.038

Kaur, J. (2014). A Comprehensive Review on Metabolic Syndrome. Cardiol. Res. Pract. 2014, 1-21. doi:10.1155/2014/943162 
Kesharwani, P., Gorain, B., Low, S. Y., Tan, S. A., Ling, E. C. S., Lim, Y. K., et al. (2018). Nanotechnology Based Approaches for Anti-diabetic Drugs Delivery. Diabetes Res. Clin. Pract. 136, 52-77. doi:10.1016/J.DIABRES.2017.11.018

Keshetty, V., Gudipati, R., Mohan Kandukuri, J., and Allenki, V. (2009). Antihyperlipidemic Activity of Methanolic Extract of Garlic (Allium Sativum L.) in Triton X-100 Induced Hyperlipidemic Rats. J. Pharm. Res. 2 (5), 777-780. Available: www.phresearchjournal.info (Accessed Oct 13, 2021).

Khorasani, S., Danaei, M., and Mozafari, M. R. (2018). Nanoliposome Technology for the Food and Nutraceutical Industries. Trends Food Sci. Techn. 79, 106-115. doi:10.1016/J.TIFS.2018.07.009

Kikuchi, N., Satoh, K., Kurosawa, R., Yaoita, N., Elias-Al-Mamun, M., Siddique, M. A. H., et al. (2018). Selenoprotein P Promotes the Development of Pulmonary Arterial Hypertension. Circulation 138 (6), 600-623. doi:10.1161/ CIRCULATIONAHA.117.033113

Kopelman, P. G. (2000). Obesity as a Medical Problem. Nature 404 (6778), 635-643. doi:10.1038/35007508

Lee, M.-S., Jung, S., Shin, Y., Lee, S., Kim, C.-T., Kim, I.-H., et al. (2017). Lipolytic Efficacy of Alginate Double-Layer Nanoemulsion Containing Oleoresin Capsicum in Differentiated 3T3-L1 Adipocytes. Food Nutr. Res. 61, 1339553. doi:10.1080/16546628.2017.1339553

Li, F., Shi, Y., Liang, J., and Zhao, L. (2019). Curcumin-loaded Chitosan Nanoparticles Promote Diabetic Wound Healing via Attenuating Inflammation in a Diabetic Rat Model. J. Biomater. Appl. 34 (4), 476-486. doi:10.1177/0885328219860929

Liu, L., Chen, Z., Wang, J., Li, R., Li, T., Chang, M., et al. (2018). Encapsulation of Curcumin Nanoparticles with MMP9-Responsive and Thermos-Sensitive Hydrogel Improves Diabetic Wound Healing. ACS Appl. Mater. Inter. 10 (19), 16315-16326. doi:10.1021/ACSAMI.8B03868

Liu, Y., Zeng, S., Liu, Y., Wu, W., Shen, Y., Zhang, L., et al. (2018). Synthesis and Antidiabetic Activity of Selenium Nanoparticles in the Presence of Polysaccharides from Catathelasma Ventricosum. Int. J. Biol. Macromolecules 114, 632-639. doi:10.1016/J.IJBIOMAC.2018.03.161

Ma, J., Yang, H., Basile, M. J., and Kennelly, E. J. (2004). Analysis of Polyphenolic Antioxidants from the Fruits of Three Pouteria Species by Selected Ion Monitoring Liquid Chromatography-Mass Spectrometry. J. Agric. Food Chem. 52, 5873-5878. doi:10.1021/jf049950k

Madane, R. G., and Mahajan, H. S. (2016). Curcumin-loaded Nanostructured Lipid Carriers (NLCs) for Nasal Administration: Design, Characterization, and In Vivo Study. Drug Deliv. 23 (4), 1326-1334. doi:10.3109/10717544. 2014.975382

Maity, S., Mukhopadhyay, P., Kundu, P. P., and Chakraborti, A. S. (2017). Alginate Coated Chitosan Core-Shell Nanoparticles for Efficient Oral Delivery of Naringenin in Diabetic Animals-An In Vitro and In Vivo Approach. Carbohydr. Polym. 170, 124-132. doi:10.1016/J.CARBPOL.2017.04.066

Manach, C., Scalbert, A., Morand, C., Rémésy, C., and Jiménez, L. (2004). Polyphenols: Food Sources and Bioavailability. Am. J. Clin. Nutr. 79 (5), 727-747. doi:10.1093/AJCN/79.5.727

Manju, S., and Sreenivasan, K. (2011). Synthesis and Characterization of a Cytotoxic Cationic Polyvinylpyrrolidone-Curcumin Conjugate. J. Pharm. Sci. 100 (2), 504-511. doi:10.1002/JPS.22278

Manne, A. A., Arigela, B., Giduturi, A. K., Komaravolu, R. K., Mangamuri, U., and Poda, S. (2021). Pterocarpus Marsupium Roxburgh Heartwood Extract/ chitosan Nanoparticles Loaded Hydrogel as an Innovative Wound Healing Agent in the Diabetic Rat Model. Mater. Today Commun. 26, 101916. doi:10. 1016/J.MTCOMM.2020.101916

McCracken, E., Monaghan, M., and Sreenivasan, S. (2018). Pathophysiology of the Metabolic Syndrome. Clin. Dermatol. 36 (1), 14-20. doi:10.1016/J. CLINDERMATOL.2017.09.004

Meghwani, H., Prabhakar, P., Mohammed, S., Dua, P., Seth, S., Hote, M., et al. (2018). Beneficial Effect of Ocimum Sanctum (Linn) against MonocrotalineInduced Pulmonary Hypertension in Rats. Medicines 5 (2), 34. doi:10.3390/ MEDICINES5020034

Mukhopadhyay, P., Maity, S., Mandal, S., Chakraborti, A. S., Prajapati, A. K., and Kundu, P. P. (2018). Preparation, Characterization and In Vivo Evaluation of $\mathrm{pH}$ Sensitive, Safe Quercetin-Succinylated Chitosan-Alginate Core-Shellcorona Nanoparticle for Diabetes Treatment. Carbohydr. Polym. 182, 42-51. doi:10.1016/J.CARBPOL.2017.10.098
Naseri, R., Farzaei, F., Haratipour, P., Nabavi, S. F., Habtemariam, S., Farzaei, M. H., et al. (2018). Anthocyanins in the Management of Metabolic Syndrome: A Pharmacological and Biopharmaceutical Review. Front. Pharmacol. 9, 1310. doi:10.3389/FPHAR.2018.01310

Oh, Y. S., Bae, G. D., Baek, D. J., Park, E.-Y., and Jun, H.-S. (2018). Fatty AcidInduced Lipotoxicity in Pancreatic Beta-Cells during Development of Type 2 Diabetes. Front. Endocrinol. 9, 384. doi:10.3389/FENDO.2018.00384

Pan, Y., and Kong, L.-D. (2018). High Fructose Diet-Induced Metabolic Syndrome: Pathophysiological Mechanism and Treatment by Traditional Chinese Medicine. Pharmacol. Res. 130, 438-450. doi:10.1016/J.PHRS.2018.02.020

Pateliya, B., Burade, V., and Goswami, S. (2021). Combining Naringenin and Metformin with Doxorubicin Enhances Anticancer Activity against TripleNegative Breast Cancer In Vitro and In Vivo. Eur. J. Pharmacol. 891, 173725. doi:10.1016/J.EJPHAR.2020.173725

Payab, M., Hasani-Ranjbar, S., Shahbal, N., Qorbani, M., Aletaha, A., HaghiAminjan, H., et al. (2020). Effect of the Herbal Medicines in Obesity and Metabolic Syndrome: A Systematic Review and Meta-analysis of Clinical Trials. Phytotherapy Res. 34 (3), 526-545. doi:10.1002/PTR.6547

Piazzini, V., Micheli, L., Luceri, C., D’Ambrosio, M., Cinci, L., Ghelardini, C., et al. (2019). Nanostructured Lipid Carriers for Oral Delivery of Silymarin: Improving its Absorption and In Vivo Efficacy in Type 2 Diabetes and Metabolic Syndrome Model. Int. J. Pharmaceutics 572, 118838. doi:10.1016/ J.IJPHARM.2019.118838

Ponnanikajamideen, M., Rajeshkumar, S., Vanaja, M., and Annadurai, G. (2019). In Vivo Type 2 Diabetes and Wound-Healing Effects of Antioxidant Gold Nanoparticles Synthesized Using the Insulin Plant Chamaecostus Cuspidatus in Albino Rats. Can. J. Diabetes 43 (2), 82-89. doi:10.1016/J.JCJD.2018.05.006

Ponnappan, N., and Chugh, A. (2015). Nanoparticle-Mediated Delivery of Therapeutic Drugs. Pharm. Med. 29 (3), 155-167. doi:10.1007/S40290-0150096-4

Prabhu, S., Vinodhini, S., Elanchezhiyan, C., and Rajeswari, D. (2018). Retracted : Evaluation of Antidiabetic Activity of Biologically Synthesized Silver Nanoparticles Using Pouteria Sapota in Streptozotocin-induced Diabetic Rats. J. Diabetes 10 (1), 28-42. doi:10.1111/1753-0407.12554

Ragavan, G., Muralidaran, Y., Sridharan, B., Nachiappa Ganesh, R., and Viswanathan, P. (2017). Evaluation of Garlic Oil in Nano-Emulsified Form: Optimization and its Efficacy in High-Fat Diet Induced Dyslipidemia in Wistar Rats. Food Chem. Toxicol. 105, 203-213. doi:10.1016/J.FCT.2017.04.019

Rambaran, T. F. (2020). Nanopolyphenols: a Review of Their Encapsulation and Anti-diabetic Effects. SN Appl. Sci. 282 (8), 1-26. doi:10.1007/S42452-020-3110-8

Rani, R., Dahiya, S., Dhingra, D., Dilbaghi, N., Kim, K.-H., and Kumar, S. (2018). Improvement of Antihyperglycemic Activity of Nano-Thymoquinone in Rat Model of Type-2 Diabetes. Chemico-Biological Interactions 295, 119-132. doi:10.1016/J.CBI.2018.02.006

Rasheed, H. M., Khan, T., Wahid, F., Khan, R., and Shah, A. J. (2015). Chemical Composition and Vasorelaxant and Antispasmodic Effects of Essential Oil fromRosa indicaL. Petals. Evidence-Based Complement. Altern. Med. 2015, 1-9. doi:10.1155/2015/279247

Reaven, G. M. (1988). Role of Insulin Resistance in Human Disease. Diabetes 37 (12), 1595-1607. doi:10.2337/DIAB.37.12.1595

Rice, K. M., Manne, N. D. P. K., Kolli, M. B., Wehner, P. S., Dornon, L., Arvapalli, R., et al. (2015). Curcumin Nanoparticles Attenuate Cardiac Remodeling Due to Pulmonary Arterial Hypertension. Artif. Cell Nanomedicine, Biotechnol. 44 (8), 1909-1916. doi:10.3109/21691401.2015.1111235

Roberts, C. K., Hevener, A. L., and Barnard, R. J. (2013). Metabolic Syndrome and Insulin Resistance: Underlying Causes and Modification by Exercise Training. Compr. Physiol. 3 (1), 1-58. doi:10.1002/CPHY.C110062

Rochlani, Y., Pothineni, N. V., Kovelamudi, S., and Mehta, J. L. (2017). Metabolic Syndrome: Pathophysiology, Management, and Modulation by Natural Compounds. Ther. Adv. Cardiovasc. Dis. 11 (8), 215-225. doi:10.1177/ 1753944717711379

Salim, B. (2005). Diabetes Mellitus and its Treatment. Int. J. Diabetes Metab. 13, 111-134. https://pesquisa.bvsalud.org/portal/resource/pt/emr-171007

Sambu, N. K., Kashinath, R. T., and Ambekar, J. G. (2015). Effect of Diallyl Disulphide on Diabetes Induced Dyslipidemia in Male Albino Rats. Jcdr 9 (4), BF01. doi:10.7860/JCDR/2015/13374.5860 
Saratale, G. D., Saratale, R. G., Benelli, G., Kumar, G., Pugazhendhi, A., Kim, D.-S., et al. (2017). Anti-diabetic Potential of Silver Nanoparticles Synthesized with Argyreia Nervosa Leaf Extract High Synergistic Antibacterial Activity with Standard Antibiotics against Foodborne Bacteria. J. Clust Sci. 28, 1709-1727. doi:10.1007/s10876-017-1179-z

Sawicki, T., Topolska, J., Romaszko, E., and Wiczkowski, W. (2018). Profile and Content of Betalains in Plasma and Urine of Volunteers after Long-Term Exposure to Fermented Red Beet Juice. J. Agric. Food Chem. 66 (16), 4155-4163. doi:10.1021/ACS.JAFC.8B00925

Sengottaiyan, A., Aravinthan, A., Sudhakar, C., Selvam, K., Srinivasan, P., Govarthanan, M., et al. (2016). Synthesis and Characterization of Solanum Nigrum-Mediated Silver Nanoparticles and its Protective Effect on AlloxanInduced Diabetic Rats. J. Nanostruct Chem. 6, 41-48. doi:10.1007/s40097-0150178-6

Shi, J., Arunasalam, K., Yeung, D., Kakuda, Y., Mittal, G., and Jiang, Y. (2004). Saponins from Edible Legumes: Chemistry, Processing, and Health Benefits. J. Med. Food 7 (1), 67-78. Available: www.liebertpub.com (Accessed Oct 13, 2021).

Shin, H.-S., Han, J.-M., Kim, H.-G., Choi, M.-K., Son, C.-G., Yoo, H.-R., et al. (2014). Anti-atherosclerosis and Hyperlipidemia Effects of Herbal Mixture, Artemisia Iwayomogi Kitamura and Curcuma Longa Linne, in Apolipoprotein E-Deficient Mice. J. Ethnopharmacology 153 (1), 142-150. doi:10.1016/J.JEP. 2014.01.039

Singh, S. V., Shrivastava, A., Jyotshna, fnm., Chaturvedi, U., Singh, S. C., Shanker, K., et al. (2016). A Mechanism-Based Pharmacological Evaluation of Efficacy of Flacourtia Indica in Management of Dyslipidemia and Oxidative Stress in Hyperlipidemic Rats. J. Basic Clin. Physiol. Pharmacol. 27 (2), 121-129. doi:10. 1515/JBCPP-2015-0017

Singla, R., Soni, S., Patial, V., Kulurkar, P. M., Kumari, A., S., M., et al. (2017). Cytocompatible Anti-microbial Dressings of Syzygium Cumini Cellulose Nanocrystals Decorated with Silver Nanoparticles Accelerate Acute and Diabetic Wound Healing. Sci. Rep. 7 (1), 1-13. doi:10.1038/s41598-01708897-9

Singla, R., Soni, S., Patial, V., Kulurkar, P. M., Kumari, A., S., M., et al. (2017). In Vivo diabetic Wound Healing Potential of Nanobiocomposites Containing Bamboo Cellulose Nanocrystals Impregnated with Silver Nanoparticles. Int. J. Biol. Macromolecules 105, 45-55. doi:10.1016/J.IJBIOMAC.2017.06.109

Skalickova, S., Milosavljevic, V., Cihalova, K., Horky, P., Richtera, L., and Adam, V. (2017). Selenium Nanoparticles as a Nutritional Supplement. Nutrition 33, 83-90. doi:10.1016/J.NUT.2016.05.001

Sounderya, N., and Zhang, Y. (2008). Use of Core/Shell Structured Nanoparticles for Biomedical Applications. Biomeng 1 (1), 34-42. doi:10.2174/ 1874764710801010034

Srikanth, S., and Deedwania, P. (2016). Management of Dyslipidemia in Patients with Hypertension, Diabetes, and Metabolic Syndrome. Curr. Hypertens. Rep. 18 (10), 1-10. doi:10.1007/S11906-016-0683-0

Subramani, K., Pathak, S., and Hosseinkhani, H. (2012). Recent Trends In Diabetes Treatment Using Nanotechnology. Dig. J. Nanomater. Biostructures 7 (1), 85-95. https://www.chalcogen.ro/85_Subramani.pdf

Sun, Y.-E., Wang, W., and Qin, J. (2018). Anti-hyperlipidemia of Garlic by Reducing the Level of Total Cholesterol and Low-Density Lipoprotein. Medicine (Baltimore) 97, e0255. doi:10.1097/MD.0000000000010255

Tabatabaei-Malazy, O., Larijani, B., and Abdollahi, M. (2015). Targeting Metabolic Disorders by Natural Products. J. Diabetes Metab. Disord. 14 (1), 1-21. doi:10. 1186/S40200-015-0184-8

Tan, D., Wang, Y., Bai, B., Yang, X., and Han, J. (2015). Betanin Attenuates Oxidative Stress and Inflammatory Reaction in Kidney of Paraquat-Treated Rat. Food Chem. Toxicol. 78, 141-146. doi:10.1016/J.FCT.2015.01.018

Vaziri, N. D., Xu, Z.-G., Shahkarami, A., Huang, K. T., Rodruguez-Iturbe, B., and Natarajan, R. (2005). Role of AT-1 Receptor in Regulation of Vascular MCP-1, IL-6, PAI-1, MAP Kinase, and Matrix Expressions in Obesity. Kidney Int. 68 (6), 2787-2793. doi:10.1111/J.1523-1755.2005.00750.X

Wat, E., Ng, C. F., Koon, C. M., Wong, E. C. W., Tomlinson, B., and Lau, C. B. S. (2016). The Protective Effect of Herba Cistanches on Statin-Induced
Myotoxicity In Vitro. J. Ethnopharmacology 190, 68-73. doi:10.1016/J.JEP. 2016.06.020

Xiang, L., Li, Y., Deng, X., Kosanovic, D., Schermuly, R. T., and Li, X. (2018). Natural Plant Products in Treatment of Pulmonary Arterial Hypertension. Pulm. Circ. 8 (3), 1-20. doi:10.1177/2045894018784033

Xu, D., Li, Y., Zhang, B., Wang, Y., Liu, Y., Luo, Y., et al. (2016). Resveratrol Alleviate Hypoxic Pulmonary Hypertension via Anti-inflammation and Antioxidant Pathways in Rats. Int. J. Med. Sci. 13 (12), 942-954. doi:10.7150/IJMS. 16810

Xu, T., Liu, S., Ma, T., Jia, Z., Zhang, Z., and Wang, A. (2017). Aldehyde Dehydrogenase 2 Protects against Oxidative Stress Associated with Pulmonary Arterial Hypertension. Redox Biol. 11, 286-296. doi:10.1016/J. REDOX.2016.12.019

Xu, X., Shi, F., Wei, Z., and Zhao, Y. (2016). Nanostructured Lipid Carriers Loaded with Baicalin: An Efficient Carrier for Enhanced Antidiabetic Effects. Phoog Mag. 12 (47), 198. doi:10.4103/0973-1296.186347

Yi, M. H., Simu, S. Y., Ahn, S., Aceituno, V. C., Wang, C., Mathiyalagan, R., et al. (2020). Anti-obesity Effect of Gold Nanoparticles fromDendropanax Morbifera Léveilleby Suppression of Triglyceride Synthesis and Downregulation of PPAR $\gamma$ and CEBPa Signaling Pathways in 3T3-L1 Mature Adipocytes and HepG2 Cells. Cnano 16 (2), 196-203. doi:10.2174/ 1573413716666200116124822

Yin, X., Fu, X., Cheng, H., and Liang, L. (2020). a-Tocopherol and Naringenin in Whey Protein Isolate Particles: Partition, Antioxidant Activity, Stability and Bioaccessibility. Food Hydrocolloids 106, 105895. doi:10.1016/J.FOODHYD. 2020.105895

Zhang, X., Qi, J., Lu, Y., Hu, X., He, W., and Wu, W. (2014). Enhanced Hypoglycemic Effect of Biotin-Modified Liposomes Loading Insulin: Effect of Formulation Variables, Intracellular Trafficking, and Cytotoxicity. Nanoscale Res. Lett. 919 (1), 1-10. doi:10.1186/1556-276X-9-185

Zhang, Y., Li, J., Wang, Z., Xu, M.-Z., Zeng, Z., Huang, J.-p., et al. (2020). Natural Plant-Derived Polygalacturonic Acid-Oleanolic Acid Assemblies as OralDelivered Nanomedicine for Insulin Resistance Treatment. Chem. Eng. J. 390, 124630. doi:10.1016/J.CEJ.2020.124630

Zheng, H. M., Li, H. B., Wang, D. W., and Liu, D. (2013). Preparation Methods for Monodispersed Garlic Oil Microspheres in Water Using the Microemulsion Technique and Their Potential as Antimicrobials. J. Food Sci. 78 (8), N1301-N1306. doi:10.1111/1750-3841.12208

Zimmet, P., Alberti, K. G. M. M., and Shaw, J. (2001). Global and Societal Implications of the Diabetes Epidemic. Nature 414 (6865), 782-787. doi:10. 1038/414782a

Zu, Y., Zhao, L., Hao, L., Mechref, Y., Zabet-Moghaddam, M., Keyel, P. A., et al. (2021). Browning white Adipose Tissue Using Adipose Stromal Cell-Targeted Resveratrol-Loaded Nanoparticles for Combating Obesity. J. Controlled Release 333, 339-351. doi:10.1016/J.JCONREL.2021.03.022

Conflict of Interest: The authors declare that the research was conducted in the absence of any commercial or financial relationships that could be construed as a potential conflict of interest.

Publisher's Note: All claims expressed in this article are solely those of the authors and do not necessarily represent those of their affiliated organizations, or those of the publisher, the editors and the reviewers. Any product that may be evaluated in this article, or claim that may be made by its manufacturer, is not guaranteed or endorsed by the publisher.

Copyright (c) $2022 \mathrm{Hu}$, Sun, Wang and Shang. This is an open-access article distributed under the terms of the Creative Commons Attribution License (CC $B Y)$. The use, distribution or reproduction in other forums is permitted, provided the original author(s) and the copyright owner(s) are credited and that the original publication in this journal is cited, in accordance with accepted academic practice. No use, distribution or reproduction is permitted which does not comply with these terms. 